\title{
Complementary and Alternative Medicine Use among Gynaecological Cancer Patients in Enugu, South-East Nigeria
}

\author{
Leonard Ogbonna Ajah ${ }^{1}$, Dickson Tochukwu Ifezuoke ${ }^{1}$, Monique Iheoma Ajah ${ }^{2}$, \\ Theophilus Ogochukwu Nwankwo ${ }^{1}$, Ijeoma Victoria Ezeome ${ }^{1}$, Uchenna Anthony Umeh ${ }^{1} \&$ Polycarp Uche Agu ${ }^{1}$ \\ ${ }^{1}$ Department of Obstetrics and Gynaecology, University of Nigeria Teaching Hospital, Ituku-Ozalla, Enugu, \\ Nigeria \\ ${ }^{2}$ Institute of Maternal and Childhealth, University of Nigeria, Enugu Campus, Nigeria \\ Correspondence: Dr. Leonard Ogbonna Ajah, Gynaecological Oncology unit, Department of Obstetrics and \\ Gynaecology, University of Nigeria Teaching Hospital, Ituku-Ozalla, Enugu, Nigeria. Tel: 234-803-392-0789.
}

Received: April 18, 2021 Accepted: June 13, 2021 Online Published: July 23, 2021

doi:10.5539/gjhs.v13n9p16 URL: https://doi.org/10.5539/gjhs.v13n9p16

\begin{abstract}
Introduction: The high cost and associated adverse effects of conventional therapy make the patients seek complementary and alternative medicine. Complementary and alternative medicine use may contribute to the delay the patients have before seeking orthodox care.
\end{abstract}

Objectives: To determine the prevalence, pattern, factors responsible for complementary and alternative medicine use and if complementary and alternative medicine use causes delay in seeking orthodox care among gynaecological cancer patients in Enugu.

Material and Methods: A pretested, semi-structured interviewer-administered questionnaire -based cross-sectional survey of 396 eligible gynaecological cancer patients recruited from both University of Nigeria Teaching Hospital, Enugu and Enugu State University of Science and Technology Teaching Hospital, Enugu between January, 2018 and June, 2020. The data was analyzed using the statistical package for social sciences version 23 (IBM SPSS, Chicago, IL).

Results: The mean age of the respondents was 57.3 years and it ranged from 41 to 77 years. Cervical cancer (76\%) was the most common type of gynaecological cancer. A total of $283(71.5 \%)$ of the respondents used complementary and alternative medicine. Herbs $(65 \%)$ were the most common type of complementary and alternative medicine used. Majority (56.9\%) of complementary and alternative medicine users rarely used it. A total of $178(62.8 \%)$ complementary and alternative medicine users presumed that it would cure them while 105 (37.1\%) presumed that it would relieve the symptoms of their cancer. However, 197 (69.6\%) complementary and alternative medicine users stated that there was no actual benefit from its use. The low educational status has a statistically significant influence on complementary and alternative medicine use among the respondents $(\mathrm{P}$-value $=<0.0001)$. Complementary and alternative medicine use had a significant influence on delay to seek orthodox care among the study participants $(\mathrm{P}-\mathrm{value}=<0.0001)$. Majority $(84.5 \%)$ of the doctors, caring for the patients, were not aware of the patients' use of complementary and alternative medicine.

Conclusion: Complementary and alternative medicine use among gynaecological cancer patients is high in Enugu. It also delays their presentation for orthodox care. Female education and public sensitization on the effect of complementary and alternative medicine use is necessary to curb this trend.

Keywords: complementary and alternative medicine, gynaecological cancer, delay, Enugu

\section{Introduction:}

Gynaecological cancers comprise cancers of the vulva, vagina, uterus, fallopian tubes and ovaries. Apart from the cervical cancer which has a screening method and can be detected early, most gynaecological cancer patients present late (WHO, 2016). The conventional therapies of gynaecological cancers such as surgery, chemotherapy, radiotherapy, and hormonal therapy are usually expensive and some aspects of them have much adverse effect, and often force patients to seek complementary and alternative therapy (Al-maggar et al., 2013; Ezeome \& Anarado, 2007). Complementary and alternative medicine (CAM) is defined as medical and health systems, practices, and products that are not currently considered as an integral parts of conventional medicine (NCCI, 2016; Algier et al., 
2005). Each particular therapy isconsidered as complementary if it is used in addition to conventional medical treatment. On the other hand, it is viewed as alternative if the patient decides to use it in place of a prescribed allopathic treatment (NCCI, 2016). Drug interaction between CAM and chemotherapy or radiotherapy or both has a potentially hazardous outcome and can also be associated with cancer treatment delay (Lee et al., 2006; Gupta et al., 2006; Davis et al., 2005).

Based on World Health Organization report, the global prevalence of CAM use ranges from 30 to $75 \%$ (WHO, 2002). Because of this high prevalence, about $88 \%$ of countries in the world are integrating certain aspects of CAM into their healthcare policy (WHO, 2019). Approximately 35.9\% of cancer patients in Europe use CAM (Molassiotis et al., 2006). Also 61.2\% of gynaecological oncology patients in Turkey used CAM (Nazik et al., 2012). Ezeome et al reported 65\% of CAM use among surgical oncology patients in Enugu (Ezeome \& Anarado, 2007). Similarly, Nwankwo et al reported that $64.3 \%$ of gynaecological cancer patients used CAM in the same centre (Nwankwo et al., 2019). The high prevalence of CAM use among cancer patients in these studies could be attributed to the traditional nature of the society, cultural affinity, religious beliefs and practices, high cost of allopathic treatment and ignorance.

Cancer patients take a wide range of CAM and they include ingested therapies such as herbs, homeopathic remedies, psychological, physical and spiritual techniques (Nwankwo et al., 2019; Verhoef et al., 2005; Ernst \& Cassileth, 1998). The reasons while oncology patients resort to CAM use comprise symptom and side effect relief, improving physical and/or emotional well being, perceived improvement in quality of life, desire for greater control and participation and perceived effectiveness of CAM (Lengacher et al., 2006; Ernst, 2000; Friedman et al., 1997). The allopathic related factors for CAM use by cancer patients include dissatisfaction with some aspects of conventional health care like adverse effects and high cost, poor doctor-patient relationship, poor accessibility of conventional care and poverty (Ernst, 2000).

Because CAM use is engraved in Nigerian culture and predates allopathic medicine use, there seems to be less restrictive regulation of CAM when compared with allopathic medicine use. Paradoxically, some herbal medicines have been shown to contain toxic substances that are injurious to health (Sharwan et al., 2015). This may affect the health of gynaecological cancer patients. CAM practitioners have been accused of exaggerated claims without having scientific data about treatment effectiveness, thus making it difficult to ascertain the legitimacy and effectiveness of the therapy (Abolfotouh et al., 2013). Inadequate coordination of the practitioners' activities, poor communication between the practitioners and their patients, secrecy of treatment content and difficulty in determining treatment ingredients are some of the drawbacks of CAM (FRN, 2010; Donkor, 2008). In addition, incorrect diagnosis, imprecise dosage, low hygiene standards, and absence of documentation adversely affect the authenticity of CAM especially in sub-Saharan Africa. Though there have been previous studies on CAM use among cancer patients in Enugu (Nwankwo et al., 2019; Ezeome \& Anarado, 2007), there are however paucity of studies on determination of, if CAM use causes delay in seeking orthodox care among gynaecological cancer patients. Delay before seeking orthodox care has contributed to maternal mortality in Nigera (Okonofua et al., 2017). Besides, the previous studies in Enugu were single-centre studies while the current one is a multi-centre study. This study is therefore aimed at determining the prevalence, pattern, predictors of CAM use and if CAM use causes delay in seeking orthodox care among gynaecological cancer patients in Enugu,South-East Nigeria. The finding from this study could help bridge the knowledge gap and possibly help in policy formulation towards solving the problem.

\section{Material and Methods}

\subsection{Study Area}

Enugu state is one of the five states in south-East Nigeria. It is bounded in the north-west by Kogi State, north-east by Benue State, east by Ebonyi State, west by Anambra State and south by AbiaState. The state has a population of $3,267,837$ according to the 2006 population census (FRN, 2010). Enugu State is predominantly Igbo but there are pockets of other tribes.

\subsection{Study Centres}

The study sites were purposively selected. The University of Nigeria Teaching Hospital (UNTH) is a 500 bed tertiary hospital located in a 306 -hectare expanse of Land in Ituku-Ozalla. The hospital is along Enugu-Port Harcourt Expressway and about 21 kilometres from Enugu metropolis. It has a functional oncology centre and serves as a referral centre to other hospitals in South-East, South-South and North-Central Nigeria. Certain specialized cases are also referred from Cameroun. The availability of radiotherapy services at the hospital has further increased referral of cancer cases to the centre. 
Enugu State University of Science and Technology (ESUT) Teaching Hospital, Park Lane, Government Reserved Area (GRA), Enugu is a tertiary hospital located in Enugu metropolis. It also has a gynaecological oncology unit and gets referrals from other hospitals in Enugu State and neighbouring states.

\subsection{Study Population}

This comprised all gynaecological cancer patients attending gynaecological oncology clinics or admitted in the wards with histology diagnosis of gynaecological cancer.

\subsection{Study Design}

This was a cross sectional descriptive study in which interviewer-administered semi-structured questionnaireswere usedto collect information from eligible participants between January, 2018 and June, 2020. Prior to this study, the questionnaires were pretested on 10 gynaecological cancer patients at Alex Ekwueme University Teaching Hospital, Abakaliki, Ebonyi State. The number of patients recruited at each of the study centres was based on the proportion of patient load at such centres. The eligible participants were consecutively recruited after individual counselling and consent was obtained from each of them. The first step in administering the questionnaire was assurance section, in which the patients were informed that the information sought was not part of their treatment and would no way influence the treatment of their cancer. The questionnaire comprised the socio-demographic data, the type of cancer, when the patient noticed the symptoms, when she presented for orthodox treatment, previous treatment received (if any) and the current treatment being received, information on the stage of the disease (this was obtained from the case notes), whether the patient had used CAM and whether CAM use by the participants contributed to delay in their seeking orthodox care. For the purpose of this study, participants who used CAM daily during the current cancer treatment were regarded as very often users, those that used CAM two to three times in a week were regarded as often users while those that used CAM less than two times a week but more than once per month were regarded as rare users. Those that used CAM once per month were regarded as very rare users. Also the participants who had used CAM prior to onset of the cancer and those who had never used CAM where regarded as non users. CAM use delay was assessed by obtaining information on when the respondents started having the symptoms of the disease, if they started using CAM because of the symptoms and when they sought for orthodox care. The gynaecological cancer patients who presented at stages 1 and 2 were regarded as presenting in early stages while those who presented at stages 3 and 4 were regarded as presenting in advanced or late stages of the cancer.

\subsection{Sample Size Determination}

The minimal sample size for the study was calculated using the formula for cross-sectional studies (Charan \& Biswas, 2013):

$$
\mathrm{n}=\mathrm{z}^{2} \mathrm{pq} / \mathrm{d}^{2}
$$

$\mathrm{n}=$ minimum sample size; $\mathrm{z}=$ standard normal deviate at $95 \%$; confidence interval $=1.96$

$\mathrm{p}=$ prevalence from a previous study on CAM use among gynaecological cancer patients in UNTH given at $64.3 \%$ (Nwankwo et al., 2019); $q=100-p$ and $d=$ level of precision/ accuracy, set at 5\%. After adding $10 \%$ attrition rate, n was 388 .

\section{Inclusion criteria}

All the consenting gynaecological cancer patients who had histological diagnosis of the cancer were included in the study.

\section{Exclusion criteria}

These comprised the patients who did not have histological diagnosis of gynaecologic cancer and those who, despite adequate counselling, declined consent to participate in the study.

\subsection{Data Analysis}

The data was analyzed using the statistical package for social sciences version 23 (IBM SPSS, Chicago, IL).Categorical variables were analysed with chi-square test. The level of significance was set at P-value $<0.05$.

\subsection{Ethical Consideration}

Ethical clearance for the study was obtained from the Human Research Ethics Committee of the University of Nigeria Teaching Hospital. The ethical approval number is NHREC/05/01/2008B-FWA00002458-1RB00002323. Institutional permission for the study was also obtained from Enugu State University of Science and Technology Teaching Hospital. 


\section{Results}

A total of $341(86.1 \%)$ and $55(13.9 \%)$ of the study participants were consecutively recruited at the University of Nigeria Teaching Hospital and Enugu State University of Science and Technology Teaching Hospital respectively. The mean age of the respondents was 57.3 years and it ranged from 41 to 77 years. A total of 303 (76.5\%), 58 $(14.6 \%), 34(8.6 \%)$ and $1(0.3 \%)$ of the participants were diagnosed of cervical cancer, endometrial cancer, ovarian cancer and vulva cancer respectively. Approximately $7 \%, 17 \%, 56 \%$ and $20 \%$ of the participants were in stages 1, 2, 3 and 4 of the gynaecological cancers respectively. Therefore majority (76\%) of the gynaecological cancer patients presented in advanced stage. The low educational status has a statistically significant influence on CAM use among the respondents. Majority $(84.5 \%)$ of the respondents stated that their doctors were not aware of their use of CAM. Doctors' history of CAM use by the respondents had a significant effect on their awareness of patients' use of CAM (P-value $=<0.0001)$.

Table 1. Socio- Demographic Characteristics of Respondents

\begin{tabular}{|c|c|c|}
\hline Socio-demographic characteristics & Frequency $(\mathrm{N}=396)$ & Percentage \\
\hline \multicolumn{3}{|l|}{ Age(years) } \\
\hline $41-50$ & 69 & $17.4 \%$ \\
\hline $51-60$ & 208 & $52.5 \%$ \\
\hline $61-70$ & 106 & $26.7 \%$ \\
\hline $71-80$ & 13 & $3.2 \%$ \\
\hline \multicolumn{3}{|l|}{ Tribe } \\
\hline Igbo & 365 & $91.9 \%$ \\
\hline Hausa & 1 & $0.3 \%$ \\
\hline Yoruba & 7 & $1.8 \%$ \\
\hline Others & 23 & $5.8 \%$ \\
\hline \multicolumn{3}{|l|}{ Religion } \\
\hline Christianity & 385 & $97.0 \%$ \\
\hline Islam & 4 & $1 \%$ \\
\hline Jewish & 3 & $0.8 \%$ \\
\hline ATR & 4 & $1 \%$ \\
\hline \multicolumn{3}{|l|}{ Marital Status } \\
\hline Single & 8 & $2 \%$ \\
\hline Married & 247 & $62.2 \%$ \\
\hline Divorced & 25 & $6.3 \%$ \\
\hline Widowed & 116 & $29.3 \%$ \\
\hline \multicolumn{3}{|l|}{ Educational Attainment } \\
\hline No formal education & 58 & $14.6 \%$ \\
\hline Primary & 165 & $41.6 \%$ \\
\hline Secondary & 116 & $29.2 \%$ \\
\hline Tertiary & 57 & $14.4 \%$ \\
\hline \multicolumn{3}{|l|}{ Job Description } \\
\hline House Wife & 85 & $21.4 \%$ \\
\hline Farmer & 162 & $40 \%$ \\
\hline Trader & 100 & $25.2 \%$ \\
\hline Civil Servant & 49 & $12.3 \%$ \\
\hline
\end{tabular}


Table 1 shows the socio-demographic characteristics of the respondents. Majority of the respondents were between 51 and 60 years old,Igbos,christians, married, farmers and had primary education.

Table 2. Prevalence, types, Frequency of use, and benefits of complementary and Alternative Medicine (CAM) use among the participants

\begin{tabular}{lcc}
\hline CAM USE (N=396) & Frequency & Percentage \\
\hline Yes & 283 & $71.5 \%$ \\
No & 113 & $28.5 \%$ \\
\hline Types of CAM used by respondents(N=283) & 184 & $65.0 \%$ \\
Herbs alone & 39 & 13.8 \\
Combined prayers with herbs & 27 & 9.5 \\
Spiritual sacrifice & 24 & 8.5 \\
Prayers alone & 9 & 3.2 \\
Medicinal tea & 11 & $3.9 \%$ \\
\hline Frequency of CAM USE $(\mathbf{N}=\mathbf{2 8 3})$ & 85 & $30.0 \%$ \\
Very Often & 161 & $56.9 \%$ \\
Often & 26 & $9.2 \%$ \\
Rarely & & \\
Very Rarely & 178 & $62.8 \%$ \\
\hline Presumed Benefit $\mathbf{~ N = 2 8 3 )}$ & 105 & $37.1 \%$ \\
Total Cure & & \\
Symptom Relief & 197 & $69.6 \%$ \\
\hline Actual benefit of CAM $(=\mathbf{2 8 3})$ & 86 & 30.4 \\
None & & \\
Little & & \\
\hline
\end{tabular}

The prevalence, types, frequency of use, and perceived benefits of CAM use among the participants were shown in Table 2. A total of 283(71.5\%) of the respondents had used CAM. The most common types of CAM used by the respondents were herbs $(65 \%)$. The majority (56.9\%) of CAM users rarely used it. A total of $178(62.8 \%)$ CAM users presumed that it would cure them while the remaining $105(37.1 \%)$ presumed that it would relieve the symptoms of their gynaecological cancer. However, 197 (69.6\%) CAM users realised that there was no actual benefit from its use.

Table 3. Influence of CAM use on orthodox care delay among the participants

\begin{tabular}{llllc}
\hline \multicolumn{1}{c}{ Variable } & \multicolumn{1}{c}{ Frequency (\%) } & \multicolumn{1}{c}{ X2 } & \multicolumn{2}{c}{ P-value } \\
\hline Delay & CAM USERS ( N= 283) & Non- CAM USERS (N=113) & $\mathbf{7 5 . 6 0 8}$ & $<\mathbf{0 . 0 0 0 1}$ \\
\multicolumn{1}{c}{ Yes } & $200(70.7 \%)$ & $25(28.4 \%)$ & & \\
No & $83(29.3 \%)$ & $88(71.6 \%)$ & & \\
\hline Delay Duration & CAM USERS (N=200) & Non- CAM USERS (N=25) & $\mathbf{4 0 . 6 7 2}$ & $<\mathbf{0 . 0 0 0 1}$ \\
$<1$ year & $13(6.5 \%)$ & $13(52 \%)$ & & \\
$1-5$ years & $186(93.0 \%)$ & $12(48 \%)$ & & \\
$6-10$ years & $1(0.5 \%)$ & $0(0 \%)$ & & \\
\hline
\end{tabular}


The influence of CAM use on orthodox care delay among the participants is shown in table 3. CAM use had a significant influence on delay to seek orthodox care among the study participants $(\mathrm{P}$-value $=<0.0001)$.

\section{Discussion}

This study showed that the prevalence of CAM use among gynaecological cancer patients in Enugu was 71.5\%. Cervical cancer was the most common gynaecological cancer recorded among the respondents. Most of the gynaecological cancer patients presented at an advanced stage. Herbs were the most common CAM used by the respondents. Majority of the patients rarely used CAM. Majority of the respondents presumed that CAM would cure them but later realised that it did not have any actual benefit. The low educational status has a statistically significant influence on CAM use among the respondents. CAM use had a significant influence on delay to seek orthodox care among the study participants. Majority of the doctors managing these patients were not aware of the patients' CAM use .The doctors' history of CAM use by respondents had a significant effect in their awareness of patients' use of CAM.

The $71.5 \%$ prevalence of CAM use from this study was essentially similar to $64.5 \%$ and $65 \%$ reported in Enugu among gynaecological and surgical oncology patients respectively (Nwankwo et al., 2019; Ezeome \& Anarado, 2007). This is however higher than $14 \%$ and $38.7 \%$ reported in Malaysia and India respectively (Al-maggar et al., 2016; Lee et al., 2006). The discrepancies in prevalence between this study and the Malaysian and Indian studies could be attributed to the difference in what constitutes CAM in the different studies. While the previous studies in Enugu and this study included prayer as part of CAM, the Indian and Malaysian studies excluded prayer. The difference in prevalence could also be attributed to the disparity in belief and cultural practices between sub-Saharan Africa and Asia. Cancer in this environment is perceived, with misconception, as being caused by spiritual forces beyond the reach of conventional medical therapy. Herbs being the most common CAM used in this study is similar to previous reports in Nigeria (Nwankwo et al., 2019; Onyiapat et al., 2017; Ezeome \& Anarado, 2007). This study showing a low educational status having a significant influence on CAM use among the respondents is similar to a previous study in Ekiti, South-west Nigeria (Aina et al., 2020). This is however contrary to a previous report by Okoronkwo et al in Enugu, South-East Nigeria which showed a relationship between CAM use and higher educational status (Okoronkwo et al., 2014).

Cervical cancer being the most common gynaecological cancer in this study is supported by previous reports in Nigeria (Abdullahi \& Ayogu, 2020; Nwankwo et al., 2019). This is contrary to reports in the developed countries like the United States of America where it is third after cancer of the corpus uteri and ovary (CDC, 2019). The disparity in cervical cancer incidence between sub-Saharan Africa and the developed countries could be attributed to inadequate cervical cancer preventive measures being carried out in sub-Saharan Africa. Majority of the patients presenting in advanced stages of gynaecological cancer in this study is similar to a previous report in Enugu (Nwankwo et al., 2019). This underscores the need for public health sensitization on cancer screening, early detection and treatment of cancers in this environment. The delay, before presentation for orthodox care, caused by CAM use by the gynaecological cancer patients in this study is supported by a previous report in the United States of America (Greenlee et al., 2016). This may have contributed to the late presentations of most of the patients in this environment. This study revealing majority of the participants expecting total cancer cure from CAM use is supported by a previous study in Turkey (Ceylan et al., 2002). However, this is contrary to a United States of American study which showed that cancer patients use CAM primarily to boost their immunity and for improvement of their quality of life such as use of radiotherapy, chemotherapy and endocrine therapy (Hammersen et al., 2020).

The poor doctors' awareness to the respondents' use of CAM in this study is similar to the previous report in Pakistan (Malik et al., 2000). This is mainly due to lack of detailed history taking among the doctors. This underscores the importance of good and detailed history taking as it might be the only opportunity to obtain the information and counsel patients against those substances and practices that might have adverse effect on them.

This study is weakened by the cross-sectional design in which some information sought from the patients are prone to recall bias. It is also a hospital-based study in which its findings may not be a true reflection in the society.

\section{Conclusion}

There is a high prevalence of CAM use among gynaecological cancer patients in Enugu, South-East Nigeria. CAM use causes delay at presentation for orthodox care among the gynaecological cancer patients. Female education and enlightenment is necessary to curb this ugly trend.

\section{Competing Interests Statement}

The authors declare that there are no competing or potential conflicts of interest. 


\section{References}

Abdullahi, H. I., \& Ayogu, M. E. (2020). Pattern and relative frequencies of gynaecological malignancies at the University of Abuja Teaching Hospital, Abuja. Trop J Obstet Gynaecol, 37, $177-81$. https://doi.org/10.4103/TJOG.TJOG_99_19

Abolfotouh, M. A., Alabdrabalnabi, A. A., Albacker, R. B., Al-Jughaiman, U. A., \& Hassan, S. N. (2013). Knowledge, attitude, and practices of infertility among Saudi couples. Int J Gen Med., 6, 563-73. https://doi.org/10.2147/IJGM.S46884

Aina, O., Gautam, L., Simkhada, P., \& Hall, S. (2020). Prevalence, determinants and knowledge about herbal medicine and non-hospital utilisation in southwest Nigeria: a cross-sectional study. BMJ Open ,10, e040769. https://doi.org/10.1136/bmjopen-2020-040769

Algier, L. A, Hanoglu, Z., Ozden, G., \& Kara, F. (2005). The use of complimentary and alternative (non-conventional)medicine in cancer patients in Turkey. European Journal of Oncology Nursing, 9(2), 138-146. https://doi.org/10.1016/j.ejon.2005.03.010

Al-maggar, R.A., Bobyrishev, Y.V., Abdughani, M., \& Osman, M. T. (2013). Complemantary and alternative medicine use among cancer patients in Malaysia. World Journal of Medical Sciences, 8(2) 157-164.

Centers for Disease Control and Prevention. (2019). Gynecologic Cancer Incidence, United States-2012-2016.USCS Data Brief, no 11. Atlanta, GA: Centers for Disease Control and Prevention, US Department of Health and Human Services.

Ceylan, S., Hamzaoğlu, O., Kömürcü, S., Beyan, C., \& Yalçin, A. (2002). Survey of the use of complementary and alternative medicine among Turkish cancer patients. Complement Ther Med., 10(2), 94-9. https://doi.org/10.1054/ctim.2002.0527

Charan, J., \& Biswas, T. (2013). How to Calculate Sample Size for Different Study Designs in Medical Research? Indian J Psychol Med., 35(2), 121-126. https://doi.org/10.4103/0253-7176.116232

Davis, G. E., Bryson, C. L., Yueh, B., McDonell, M. B., Micek, M. A., \& Fihn, S. D. (2005). Treatment delay associated with alternative medicine use among veterans with head and neck cancer. Head Neck, 28(10), 926-31. https://doi.org/10.1002/hed.20420

Donkor, E. S. (2008). Socio-Cultural Perceptions of Infertility In Ghana. African Journal of Nursing and Midwifery, $10(1), 22-34$.

Ernst, E., \& Cassileth, B. R. (1998). The prevalence of complementary/alternative medicine in cancer: a $\begin{array}{llll}\text { systematic } & \text { review. } & \text { Cancer, } & 83(4),\end{array}$ https://doi.org/10.1002/(SICI)1097-0142(19980815)83:4<777::AID-CNCR22>3.0.CO;2-O

Ernst, E. (2000). The role of complementary and alternative medicine. BMJ, 321(7269), 1133-1135. https://doi.org/10.1136/bmj.321.7269.1133

Ezeome, E. R., \& Anarado, A. N. (2007). Use of complementary and alternative medicine by cancer patients at the University of Nigeria Teaching Hospital, Enugu, Nigeria. BMC Complement Altern Med, 7(28). https://doi.org/10.1186/1472-6882-7-28

Federal Republic of Nigeria. (2010). 2006 Population and Housing Census. National Population Commission, 4, $1-371$.

Friedman, T., Slayton, W. B., Allen, L. S., Pollock, B. H., Dumont-Driscoll, M., Mehta, P., \& Graham-Pole, J. (1997). Use of alternative therapies for children with cancer. Pediatrics, 100(6), E1. https://doi.org/10.1542/peds.100.6.e1

Greenlee, H., Neugut, A. I., Falci, L., Hillyer, G. C., Buono, D., Mandelblatt, J. S., .. \& Hershman, D. L. (2016). Association Between Complementary and Alternative Medicine Use and Breast Cancer Chemotherapy Initiation: The Breast Cancer Quality of Care (BQUAL) Study. JAMA oncology, 2(9), 1170-1176. https://doi.org/10.1001/jamaoncol.2016.0685

Gupta, D., Lis, C. G., Birdsall, T. C., \& Grutsch, J. F. (2005). The use of dietary supplements in a community hospital comprehensive cancer center: implications for conventional cancer care. Support Care Cancer, 13(11), 912-9. PMID: 15856334. https://doi.org/10.1007/s00520-005-0820-9

Hammersen, F., Pursche, T., Fischer, D., Katalinic, A., \& Waldmann, A. (2020). Use of Complementary and Alternative Medicine among Young Patients with Breast Cancer. Breast Care, 15, 163-170. 
https://doi.org/10.1159/000501193

Lee, A. H., Ingraham, S. E., Kopp, M., Foraida, M. I., \& Jazieh, A. R. (2006).The incidence of potential interactions between dietary supplements and prescription medications in cancer patients at Veterans Administration Hospital. American Journal of Oncology, 29, 178-182. https://doi.org/10.1097/01.coc.0000209369.44100.25

Lengacher, C. A., Bennett, M. P., Kip, K. E., Gonzalez, L., Jacobsen, P., \& Cox, C. E. (2006). Relief of symptoms, side effects, and psychological distress through use of complementary and alternative medicine in women with breast cancer. Oncol Nurs Forum, 33(1), 97-104. https://doi.org/10.1188/06.ONF.97-104

Malik, I. A., Kahn, N. A., \& Kahn, W. (2000). Use of unconventional method of therapy by cancer patients in Pakistan. Eur J Epidemoiol, 16, 155-160.

Molassiotis, A., Browall, M., Milovics, L., Panteli, V., Patiraki, E., \& Fernandez-Ortega, P. (2006). Complementary and alternative medicine use in patients with gynecological cancers in Europe. Int J Gynecol Cancer, 16(Suppl 1), 219-24. https://doi.org/10.1111/j.1525-1438.2006.00309.x

National Center for Complementary and Integrative Health. (2016). Whatis complementary and alternative or integrative health? Retrieved from http://nccih.nih.gov/health/whatiscam/\#6-

Nazik, E., Nazik, H., Api, M., Kale, A., \& Aksu, M. (2012). Complementary and alternative medicine use by gynecologic oncology patients in Turkey. Asian Pac $J$ Cancer Prev, 13(1), 21-5. https://doi.org/10.7314/APJCP.2012.13.1.021

Nwankwo, T. O., Ajah, L. O., Ezeome, I. V., Umeh, U. A., \& Aniebue, U. U. (2019). Complementary and alternative medicine. Use and challenges among gynaecological cancer patients in Nigeria: experiences in a tertiary health institution-preliminary results. European Journal of Gynaecological Oncology. 40(1), 101-105.

Okonofua, F., Imosemi, D., Igboin, B., Adeyemi, A., Chibuko, C., Idowu, A., \& Imongan, W. (2017). Maternal death review and outcomes: An assessment in Lagos State, Nigeria. PLoS ONE, 12(12), e0188392. https://doi.org/10.1371/journal.pone.0188392

Okoronkwo, I., Onyia-pat, J., Okpala, P., Agbo, M., \& Ndu, A. (2014). Patterns of Complementary and Alternative Medicine Use, Perceived Benefits, and Adverse Effects among Adult Users in Enugu Urban, South-East Nigeria. Evidence-Based Complementary and Alternative Medicine, 2014. https://doi.org/10.1155/2014/239372

Onyiapat, J., Okafor, C., Okoronkwo, I., Anarado, A., Chukwukelu, E., Nwaneri, A., \& Okpala, P. (2017). Complementary and alternative medicine use: Results from a descriptive study of pregnant women in Udi Local Government Area of Enugu state, Nigeria. BMC Complementary and Alternative Medicine, 17, 189.

Sharwan, G., Jain, P., Pandey, R., \& Shukla, S. S. (2015). Toxicity profile of traditional herbal medicine. Journal of Ayurvedic and Herbal Medicine, 1(3), 81-90.

Verhoef, M. J., Balneaves, L. G., Boon, H. S., \& Vroegindewey, A. Reasons for and characteristics associated with complementary and alternative medicine use among adult cancer patients: a systematic review. Integr Cancer Ther, 4(4), 274-86. https://doi.org/10.1177/1534735405282361

World Health Organization. (2002). Traditional Medicine. Strategy 2002-2005. Geneva: Switzerland.www.who.int/iris/handle/10665/67163/.

World Health Organization. (2016). Global cancer occurrence, causes and prevention. International Agencies for research on cancer. Retrieved from www.iarc-confrence2016.com

World Health Organization. (2019). WHO global report on traditional and complementary medicine. Retrieved from https://apps.who.int/iris/handle/10665/312342.

\section{Copyrights}

Copyright for this article is retained by the author(s), with first publication rights granted to the journal.

This is an open-access article distributed under the terms and conditions of the Creative Commons Attribution license (http://creativecommons.org/licenses/by/4.0/). 